\section{§5. Correlation between Defect Structures and Hardness in Tantalum Irradiated by Heavy lons}

Yasunaga, K., Watanabe, H., Yoshida, N. (Kyushu University), Muroga, T., Noda, N.

Tantalum is one of the candidate materials for structural components of divertors because of its high toughness, high sputtering threshold energy, high fabricability and low-activation properties. However, little is known about radiation effects at present. In the present study, detailed TEM observation and hardness estimation and post-irradiation annealing of irradiated specimens were carried out.

The material used in this study was $99.95 \%$ pure tantalum with impurities of $\sim 30$ wt. ppm O, $\sim 20$ wt. ppm $\mathrm{N}$ and $\sim 30$ wt. ppm C. After cold rolling and punching into TEM disks, the specimens were annealed at $2073 \mathrm{~K}$ for $300 \mathrm{sec}$ in a vacuum of $<3 \times 10^{-5} \mathrm{~Pa}$ for recrystallization. Irradiation was performed with 2.4 $\mathrm{MeV} \mathrm{Cu}{ }^{2+}$ ions at several temperatures between R.T. and $1073 \mathrm{~K}$ using a Tandem type accelerator in Kyushu University. The damage level of the irradiation varied from 0.03 to $3 \mathrm{dpa}$ at its peak position of damage. The peak damage depth calculated by the TRIM3D code was $340 \mathrm{~nm}$. After the irradiation, specimens were backthinned by electropolishing with a solution of $2.5 \% \mathrm{HF}$, $5 \% \quad \mathrm{H}_{2} \mathrm{SO}_{4}$ and $92.5 \%$ methanol at about $230 \mathrm{~K}$. Microstructures at the depth of $250 \mathrm{~nm}$ were observed with a JEM-2000EXII transmission electron microscope at Kyushu University. The micro-indentation tests were also conducted on both unirradiated and irradiated specimens at room temperature using an Elionix ENT-1100 with a load of 1gf. A triangular pyramidal diamond indentor (Berkovich-type) with a semi-apex angle of 65 degrees was used in this study.

Hardening below $573 \mathrm{~K}$ saturates at a low level. On the other hand, at temperatures between 673 and $873 \mathrm{~K}$, the hardness increases with dose and becomes about three times higher than that of unirradiated value at $3 \mathrm{dpa}$. Above $873 \mathrm{~K}$, hardening decreases with increasing temperature. It must be emphasized that the dose dependence of hardening is quite different below $573 \mathrm{~K}$ and above $673 \mathrm{~K}$. To examine the difference in defect structure, the microstructure of specimen irradiated at $573 \mathrm{~K}$ and $673 \mathrm{~K}$ up to $3 \mathrm{dpa}$ was observed. Vacancy loops of about $4 \mathrm{~nm}$ were observed in dark field images at both temperatures. A high density of voids of $<2 \mathrm{~nm}$ diameter were formed at $673 \mathrm{~K}$ but not at $573 \mathrm{~K}$. Small white spots, which are presumably due to strain field around voids, were also observed in the dark field image at $673 \mathrm{~K}$. The density of small voids is about two orders of magnitude higher than that of vacancy loops. Therefore, the difference of hardness at $573 \mathrm{~K}$ and $673 \mathrm{~K}$ is due to the existence of a high density of voids.

In order to obtain the annealing induced change in the effects of irradiation on the hardness, the hardness change as a function of isochronal annealing temperature of the specimen irradiated at R.T. and 0.3dpa was estimated. For irradiated specimens, there is a prominent hardness increase at $573-673 \mathrm{~K}$. The high hardening is maintained up to $873 \mathrm{~K}$, and then decreases with increasing the annealing temperature. On the other hand, hardness change is not observed in unirradiated specimens at any temperature.

Dark field TEM microstructure image shows that small loops and a high density of small dot defects of $\sim 1 \mathrm{~nm}$, which are probably vacancy clusters, appeared at $723 \mathrm{~K}$. At $1073 \mathrm{~K}$, dot defects are not observed in dark field images. Instead, a low density of voids of about $2 \mathrm{~nm}$ were formed. These results suggest that the hardness increase above $573 \mathrm{~K}$ is attributed to small vacancy clusters as observed $723 \mathrm{~K}$.

In conclusion, correlation of microstructure and hardness in heavy ion-irradiated pure tantalum has been studied. Significant hardening occurred under irradiation or post-irradiation annealing between $573 \mathrm{~K}-673 \mathrm{~K}$. TEM observation revealed that the formation of small voids is mainly responsible for radiation hardening in this temperature regime. 